\title{
Reducing Car Use in Canberra: A Holistic Policy Approach
}

\author{
Elizabeth P. Proctor
}

\section{Abstract}

Reducing car use allows cities to lower greenhouse gas emissions and improve population health and social welfare. Car use can be made less attractive by making driving less convenient, making other modes of transport more convenient, and by nudging people into reconsidering their habits where driving has become impractical. A mixture of all three options is optimal, and most effective with people who are open to changing their behaviour. With transport playing a complex role in everyday life, a holistic approach to its use is essential. The Australian Capital Territory (ACT) Government has sound aims regarding sustainable transport, but its Transport for Canberra: Transport for a sustainable city 2012-2031 report published in 2012 contains some contradictions and inefficiencies in the effort to shift Canberra's population away from driving as a default travel mode. The lack of evidence-based public transport plans and behaviour change programs will weaken Canberra's efforts, and the failure to reduce road supply will oppose them. The ACT Government has failed to fully seize the opportunity to reduce car use and hence improve population health and social welfare.

\section{Introduction}

The private car is being used in Canberra at a level that is not sustainable for human or environmental wellbeing. This article will look at Canberra's transport system and how it can encourage sustainable travel by targeting the most easily altered car trips through a combination of diverse policy measures. Given the urgency of reducing our greenhouse gas (GHG) emissions within this 'critical decade', the article will focus on short-run options (to the exclusion of land-use planning). It will then assess the ACT Government's current vision by reviewing the Transport for Canberra report, examining whether the proposed measures to reduce Canberran car use are evidence-based and likely to be effective. 
The ANU Undergraduate Research Journal

\section{Methodology}

This article is the result of an extensive literature review conducted with the aim of understanding factors that increase and reduce urban car use. It draws upon the author's experience gained when undertaking the 'Human Ecology' program at The Australian National University's Fenner School of Environment and Society. This approach emphasises a systems thinking approach, resulting in an understanding that car use is part of the overall function and design of a city and cannot be studied or addressed in isolation from urban form, public transport and active travel policy. A diverse range of sources and topics were therefore included. The reading list was compiled by searching ANU Library SuperSearch, ScienceDirect and ProQuest with a wide range of search terms including "reduce" "car use" "public transport/transit" "active travel" "cycling" "pedestrian" "Canberra" "transport emissions" "transport policy" "travel behaviour" "TravelSmart". Conversations with the project supervisor and others (Personal communications) provided new directions and topics for investigation throughout the process, as well as pursuing any papers frequently referenced throughout the collection. As this article assesses transport policy that is specific to Canberra, an effort has been made to use local information where available, though much parallel information exists from North America and Europe which informed the work (e.g. Appleyard, 1976; Bassett et al., 2011; Brog et al., 2009; Hass-Klau et al., 2000; Loukopoulos et al., 2005).

\section{Part 1: Why and how to reduce car use}

\section{The need to transform urban transport in Canberra}

Reducing Canberran driving will have benefits on three key scales: the planet, the city and individual residents.

Car use is a key component of Canberra's contribution to climate change. The global crisis of climate change and the need to respond is well documented, and Canberra faces the challenge of reducing per capita emissions by a factor of 22 (Moriarty \& Honnery, 2008). Transport makes up 23\% of Canberra's emissions, and since fuel efficiency gains for cars are likely to be offset by the increased inefficiency of accessing fossil fuels, that can be best reduced by cutting down on car travel (Moriarty \& Honnery, 2008; Office of the Commissioner for Sustainability and the Environment, 2008). Reducing car use is an important part of global climate change mitigation efforts, as private car travel makes up around $80 \%$ of vehicle kilometres travelled (VKT) in OECD countries (GrahamRowe et al., 2011). 
Cars are more popular in Canberra than other Australian cities at $81 \%$ of commute trips, with public transport (PT), walking and cycling playing minor roles (Office of the Commissioner for Sustainability and the Environment, 2008). Within the city of Canberra, local car VKT reductions benefit the community in the following ways: air pollution is reduced, leading to fewer cases of asthma and related health problems (ARRB Transport Research, 2002); congestion is reduced, improving all road travel (Ashton-Graham, 2008); and the nature of streets changes significantly. Streets are made safer by the presence of cyclists and pedestrians (Taylor \& Ampt, 2003), and the less traffic a street has, the more sociable its residents are - car-oriented streets degrade the social fabric of neighbourhoods (Appleyard, 1976). Those without access to cars benefit from a transport system that improves as demand increases, and better shops in walking distance that receive increased custom (Whitehead et al., 2006, cited in Santos et al., 2010; ACT Government, 2011).

On an individual scale, a person who uses cars less will be healthier and save money. Choosing any other mode of transport improves health and life expectancy, with public transport commuters far more likely to exercise for the World Health Organisation's recommended 30 minutes per day (Besser \& Dannenberg, 2005; Brog et al., 2009). Aside from reduced health costs later in life, driving less saves money, public transport being approximately half the cost of a car per kilometre, cycling 20\% and walking 10\% (including the price of shoes) (Victorian Transport Policy Institute, 2011).

\section{Why do people choose cars?}

For a government to change public attitudes towards cars and sustainable transport, it is important to understand what makes driving attractive. People use cars for practical and psychological reasons. The decision is affected by practical and social circumstances as well as values (Anable, 2005; Collins \& Chambers, 2005). A person may have values that oppose car use, but this can be outweighed by their situation or by positive social attitudes towards cars (Anable, 2005; Eriksson et al., 2010). The role of emotion is not always apparent due to the overlap between emotional and practical reasoning, with drivers citing practical reasons for choosing cars and constructing a narrative around time pressures or convenience to justify otherwise illogical and impractical behaviour (Van Exel \& Rietveld, 2009). Once the decision to drive has been made it tends to stick, regardless of logic or whether it matches the person's values (Anable, 2005; Van Exel \& Rietveld, 2009). A sound strategy to reduce driving must look beyond the nominated factors that go into travel decisions and address both the practical and emotional factors involved (Marshall \& Banister, 2000; Graham-Rowe et al., 2011). 
The ANU Undergraduate Research Journal

\section{Which car users are we addressing?}

There are already car users willing to drive less for personal and environmental benefits. It is effective to specifically target this segment of the population, sometimes described as 'aspiring environmentalists' (Anable, 2005) or 'aspiring green travellers', people who drive but wish they didn't (Prillwitz \& Barr, 2011). 'Malcontented motorists' are similar - they feel driving is their best option but are open to change (Anable, 2005). These groups can be guided to change their behaviours (Taylor \& Ampt, 2003; Tranter \& May, 2005; Beirao and Carbal, 2007; Brog et al., 2009; Graham-Rowe et al., 2011). Defined as attitudinal segments, the sizes of the groups vary, being estimated at $48 \%$ together in Anable (2005). $43 \%$ of respondents in a Belconnen travel behaviour program were interested in reducing their car use, indicating a similar level of opportunity in Canberra (Office of the Commissioner for Sustainability and the Environment, 2008). Focusing policy efforts where the existing attitudes are open to change is the most efficient way to reduce car use in a city.

'Aspiring environmentalists' and 'malcontented motorists' currently drive because they feel unable to give it up (Anable, 2005). They are willing to change their behaviour, but perceive a barrier to doing so. For some, their circumstances make driving the most practical option. In other cases, there is a misperception of the relative costs and benefits of cars and/or public transport and active transport (cycling and walking) (Ashton-Graham, C., 2008; Van Exel and Rietveld, 2009). For many drivers, continued car use is a result of practical and emotional factors, so driving needs to both become less practical and become seen to be less practical in order to affect the most people (Collins \& Chambers, 2005; Ashton-Graham, 2008; Brog et al., 2009).

\section{No silver bullets}

Driving in Canberra needs to lose its dominating appeal. Achieving this is possible by making driving directly less attractive (through 'push' measures) and by improving the alternatives ('pull' measures). The options outlined in this article have proven effective elsewhere (Ashton-Graham, 2008; Australian Greenhouse Office, 2006; Krizek et al., 2009; Santos et al., 2010) and would be appropriate for Canberra.

The intention of this article is not to identify any single best policy. People's transport decisions and needs are complex, and travel is a process shaped by many factors, including the layout of a city, the locations of home, childcare, schools, work and study, the landscape and transport systems around us, and our own feelings and attitudes towards travel (Cools et al., 2009). Delivering socially and environmentally sound transport to a city is a problem with no 
silver bullet solution (Krizek et al., 2009). A sensitive, successful transport policy has many benefits in all the areas of life that transport touches - health, equality of access, social streets, and global climate change. The complexity of our transport systems necessitates a multi-pronged response. As a result, the policy measures examined here are not intended as options off a menu, but as components of a holistic transport policy best enacted simultaneously and with attention to context.

\section{Push measures: The stick}

\section{Parking}

The most obvious way to 'push' people away from cars is to make it more expensive. Driving has many expenses which could be increased, but fixed costs like registration and vehicle stamp duties are less 'visible' to consumers and are usually ignored in everyday cost calculations (Tranter \& May, 2005). Fuel prices have little impact on car use (Eriksson et al., 2010), and a fuel tax cannot target drivers by destination, affecting rural trips as much as urban ones, despite their different access to alternative travel modes. Parking prices are an excellent candidate for pricing signalling (Beirao \& Carbal, 2007), particularly since Canberra currently has such low prices and the government spends a considerable amount constructing and maintaining public parking (ACT Government, 2011). As an ongoing cost, parking charges are frequently noted by drivers. Parking costs, like congestion charging road tolls (which are rarer and seem less likely in Canberra), can specifically target people driving to town centres which are well serviced by public transport and walking paths, making a clear link between daily out-of-pocket cost and the alternative travel choices available.

\section{Road space}

The convenience and speed of the car makes it the most attractive option in Canberra (Office of the Commissioner for Sustainability and the Environment, 2008). Reducing convenience and speed affects the practicality of the car. The relative time advantage of driving is a strong influence, with the majority of drivers willing to consider PT if it's faster than a car (Collins \& Chambers, 2005). Converting road lanes to cycle lanes or exclusive bus lanes sends a clear signal regarding which modes can enjoy low traffic and reduces road space for cars, but Canberra has very little congestion at present to make driving off-putting (ACT Government, 2011). Given Canberra's projected population growth (ACT Planning and Land Authority, 2007) and trend for increased car use (Mees et al., 2008), the simple act of not continually expanding the road capacity could eventually increase congestion and discourage peak hour driving, as well as 
freeing up for funds for use on PT and active transport infrastructure (Pedal Power ACT, 2011). Reducing the per capita allowance of road space may cancel out the positive feedback effect of getting drivers off the road; instead of making the road therefore more attractive to remaining drivers, the extra road space will continue to shrink as the population grows.

\section{Pull measures: The carrot}

Push measures are unpopular with drivers, hence the relatively unobtrusive push policies suggested. Pull measures are preferred, as they are seen as noninvasive and respectful of individual choice (Stradline et al., 2000; Loukopoulos et al., 2005), and so can be more widely and openly promoted as part of Canberra's sustainable transport effort.

\section{Public transport}

The most practical and central 'pull' measure would be to improve public transport. Without a quality PT system to switch to, pushing people out of cars is a pointless exercise (Collins \& Chambers, 2005). At present, Canberra's PT usage is lower than the national level, at $8.8 \%$ of work trips, contrasting with around 14\% in Melbourne and Brisbane (Australian Bureau of Statistics, 2009; Mees, 2009). Canberra is widely known as a car-dependent city with poor public transport (Office of the Commissioner for Sustainability and the Environment, 2008; Mees et al., 2008).

There is no one definition of an attractive, high quality PT service, but a few basic principles have emerged. PT must be affordable, frequent and close, achieving low walk and wait times (see Table 1).

Table 1: Canberra's current PT system does not meet the basic criteria to attract drivers

\begin{tabular}{|l|l|}
\hline PT criteria & $\begin{array}{l}\text { Does Canberra } \\
\text { have it? }\end{array}$ \\
\hline Affordable & Yes \\
\hline Close to home & Yes \\
\hline Frequent & No \\
\hline
\end{tabular}

Patronage will increase significantly if a service comes at a frequency of 15 minutes or greater all day (Walker, 2009), routes should be direct rather than meandering and the vehicles and waiting areas should be pleasant, safe and comfortable (Beirao \& Carbal, 2007). There is a constant trade-off between making services affordable, frequent, widely available and close to homes, with Canberra's bus network currently reaching many places at low prices, but infrequently (Walker, 2008; e.g. see Action, 2010a; Action, 2010b). The resulting low patronage means that the system requires an $80 \%$ subsidy (Territory and Municipal Services, 2011). 
Calls for better PT in the ACT are frequent and often pessimistic, particularly due to the belief that Canberra's physical layout restricts its ability to provide a good PT system (Joint Standing Committee on the National Capital and External Territories, 2008), but quality transport is not impossible. Canberra actually has a higher population density than Brisbane, but Brisbane outshines Canberra's 8.8\% PT use at 13.8\% (Mees, 2009; Australian Bureau of Statistics, 2011). These figures, alongside an account of Canberra's history of quality, low subsidy PT (\$39 million in 1984; \$98 million in 2001 - Mees, 2011), indicate that the obstacles to good PT are not physical or financial, but rather stem from a lack of evidence-based policy.

\section{Active travel}

Active travel - cycling and walking - currently plays a minor recreational role in Canberra, despite being a big part of the city's original design (Manning, 1984). Active travel rates are slightly higher in Canberra than other capital cities (Office of the Commissioner for Sustainability and the Environment, 2008), but this is partly because the PT is of such poor quality (Mees et al., 2008). Active travel makes up $6.2 \%$ of commutes in Canberra. European cities achieve active travel rates above $30 \%$ and sometimes as high as $45 \%$. In light of this, Canberra can do much better (Bassett et al., 2011).

While a consensus is developing on the need to provide quality infrastructure for active travel, exactly what key features a street or suburb needs to attract walkers and cyclists remains unclear (Krizek et al., 2009). A major literature review for Victoria's Department of Transport concluded that locally sensitive community design, quality sidewalks and perceived safety were among the most important factors (Krizek et al., 2009). More importantly, it found that the high variability in local needs and urban layouts demands holistic, sensitive policy approaches, with no one 'silver bullet' able to increase active travel (Krizek et al., 2009). In Canberra's case, the pedestrian environment is widely considered to be pleasant but improvable, with desired changes varying widely across localities (Wedderburn, 2011). The cycling network is extensive, but more can be done, particularly integrating cycling into public transport and providing end-oftrip facilities (parking, showers etc) (Wardman et al., 2007). Advocacy groups continue to report dissatisfaction with the infrastructure (Women's Centre for Health Matters, 2011; Pedal Power, undated), disputing the boast of Canberra having "one of the most extensive walking and cycling networks in Australia" (ACT Government, 2011: 37; Canberra Pedestrian Forum, 2011). Active travel will require both more funding and more detailed policy attention in order to become a more popular travel mode (Mees et al., 2008).

\section{Behaviour change programs}

Infrastructure improvements are important, but cannot by themselves cause significant behaviour change. However good the non-car transport options 
are, drivers tend to underestimate their quality and feel unable to stop driving (Ashton-Graham, 2008). Getting drivers to reconsider other transport options and discover their true quality can be done using travel change behaviour programs, most commonly known in Australia as TravelSmart.

TravelSmart programs are an entirely voluntary way of getting drivers out of cars. Willing households sign up to receive information about their travel options and are supported to try out alternative travel modes for a few weeks. The finer points of methodology and evaluation are still under debate (Australian Greenhouse Office, 2006), but TravelSmart programs have consistently shown reductions in vehicle kilometres travelled (VKT) that persist for at least 5 years (Australian Greenhouse Office, 2006; Ashton-Graham, 2008; Brog et al., 2009). VKT reduction varies depending on circumstances; it can be as low as $7 \%$ or as high as $17 \%$, with far greater results when delivered alongside PT improvements (Ashton-Graham, 2008). By changing household habits, these programs improve population health and reduce road use, creating savings for governments with a \$30 return for every \$1 invested (Ker I, 2002, cited in Ashton-Graham, 2008). TravelSmart also achieves carbon abatement at $\$ 40$ per tonne over 5 years, dropping as low as $\$ 20$ if the changes endure a full decade as they are predicted to do (Ashton-Graham, 2008). Though a relatively new addition to the policy options, TravelSmart has become a "legitimate and cost effective part of the solution to climate change" (Ashton-Graham, 2008: 14) by helping willing drivers out of their cars. TravelSmart can play an important role in Canberra as the government tries to shift the population away from car-centred travel habits.

\section{Part 2: How does Canberra compare?}

\section{Applications in Canberra: Fertile ground}

The ACT Government released the draft Transport for Canberra: Transport for a sustainable city 2011-2031 in late 2011. It outlines the government's intentions and vision for a city with a sustainable transport system that services everyone's needs. It feeds into Canberra's Weathering the Change Action Plan 2 with the twin goals of "reducing our travel by private passenger car... and making our vehicles less emissions intensive" (ACT Government, 2011:6). Canberra wants to "encourage more people to choose sustainable transport" (ACT Government, 2011: iii) over cars. The ACT Government clearly aims to make driving a less attractive option for its citizens. The following section examines whether Transport for Canberra makes use of the key strategies outlined above to achieve reduced car use. 


\section{Following the evidence}

In the areas of managing travel demand through parking costs and promoting active travel, the Transport for Canberra draft is utilising the best available information to form sound principles and strategies, although the level of commitment is generally either unstated or minimal.

The ACT Government's parking plan is based on sound evidence of a good way to manage travel demand. Though not particularly detailed, the plan includes pricing and supplying parking in a way that will reduce parking demand and 'discourage private vehicle travel' (ACT Government, 2011: 52), with plans to reduce the number of spaces in town centres (ACT Government, 2011). While the government's decision to control most of the supply non-commercially has been criticised (Planning Institute Australia, 2011), the government's overall intention of reducing the parking supply and increasing the price follows one of the most commonly recommended ways to promote sustainable transport (see Beirao and Carbal, 2007; Van Exel and Rietveld, 2009; Krizek et al., 2009).

Transport for Canberra does a fair job of capturing the underlying principles of supporting active travel, including multi-modal trip integration (being able to ride or walk as part of a bus trip), quality infrastructure and perceived safety as key concerns (Krizek et al., 2009; ACT Government, 2011). Overall, the plans fit well with the recommendations from local travel groups, with a lack of ambition and clarity being their key concern (Canberra Pedestrian Forum, 2011; Pedal Power, 2011). The improvements laid out in Transport for Canberra fall far short of those recommended in a recent active travel feasibility study for Canberra, including TravelSmart programs and widespread cycling training, and end-of-trip facilities at all major workplaces (Sinclair Knight Merz, 2009). It is worth taking local active travel groups seriously, as they can provide local and detailed feedback on infrastructure policy. They also have a potential role in supporting the government by promoting sustainable travel over car use (Santos et al., 2010). Despite the sound principles established regarding active travel, the government could do a lot more in terms of specific commitments (see Pedal Power, 2011) and funding, having spent \$17.11 per household on cycling last year in contrast with Brisbane's $\$ 66.70$ per household per annum (Cardno Eppell Olsen, 2011).

\section{Time to think again: Following some evidence}

The methods outlined in the Transport for Canberra report regarding PT improvement and sustainable travel promotion are not based on the best available evidence, and have been widely criticised (see Bresnan, 2011; Mees, 2011; Pedal 
Power ACT, 2011). While the best ways to improve PT and promote its use may remain under debate, it is not clear that the ACT Government is thoroughly following any evidence-based theory on delivering effective public transport.

Improving public transport is a major component of Transport for Canberra. The intended increases in service are a fitting part of any sustainable transport plan, but it is not clear whether the locations of the increased services will effectively attract car users or serve the general population. The frequent services (every 15 minutes or better) have been located based on a 'build it and they will come' model where the transport system attempts to pressure people into relocating: "the key message is 'for access to fast, frequent and reliable public transport services, locate on the Frequent Network"' (ACT Government, 2011:14; Walker, 2008). That means that for as long as it takes for Canberra's population distribution to change, many people will continue to live far from any frequent services, in a transport plan that is "looking forward to 2050" (Pers. comm., 2012b) to the detriment of current needs.

There are only two frequent network services (local and rapid) planned south of the Woden town centre in 2031, contrasting with four in the inner north (three of them servicing only that local area) (ACT Government, 2011). Given that the inner north houses $13 \%$ of Canberra's population, while Woden and Tuggeranong combine to house $35 \%$, it is clear that this is not based on serving the most people. It doesn't even serve the most densely populated areas. Belconnen, Tuggeranong and Gungahlin all boast population densities at least double that of the Inner North (Australian Bureau of Statistics, 2011), yet have few or no frequent local routes planned through their suburban areas for the next two decades (ACT Government, 2011).

Evidence by transport experts such as Dr Paul Mees shows that Canberra used to have high quality transport at a lower subsidy cost simply by coordinating timetables and prioritising local routes, something the ACT Greens continue to recommend (Bresnan, 2011; Mees, 2011). These methods gave Canberra a PT system on par with Melbourne's for per capita usage in previous decades (Mees, 2011); highlighting the fact that Canberra's physical landscape is not the insurmountable obstacle it is commonly believed it to be (Joint Standing Committee on the National Capital and External Territories, 2008). The departmental reshuffle that accompanied ACT Government disrupted these improvements, with the National Capital Development Commissions (NCDC) upholding an emphasis on cars while ACTION, Canberra's bus service, lost support from the reorganised Department of Territories. The bus service's subsequent fall from grace was a result of funding and policy priorities, not an inevitable outcome in the context of Canberra (Mees, 2011). 
Determining the optimal PT system is clearly a complex task, but the frequent service network proposed in Transport for Canberra is not an effective way to service the existing population or even the most densely settled parts of the city. While committing to key trunk routes along the major roads does encourage future settlement and investment (Hass-Klau et al., 2000; Walker, 2008), this could be done alongside an increased, better distributed spread of frequent local services that will both make buses more competitive alongside cars and reduce the need to own a car in order to access frequent services via "park and ride", which in the present plan will become the experience for most of southern Canberra. At present, it appears that the ACT Government is pursuing a PT policy that will fail to attract car users in large parts of the city.

It is well established that behaviour change programs can be the final piece to the puzzle of making driving less attractive. TravelSmart programs have had success across Australia, including a pilot study in Belconnen in 2007 (Australian Greenhouse Office, 2006; Office of the Commissioner for Sustainability and the Environment, 2008). The pilot program was considered a success, noted in Transport for Canberra for reducing VKT 13\% (ACT Government, 2011). In light of this, it is unclear why the government has no intention of repeating the household-based program that has proven most successful, instead supporting work-place and school-based programs that are far more variable in their success rates (Australian Greenhouse Office, 2006). The Australian Greenhouse Office has declared Australia ready for large-scale household programs, while noting that both workplace and school programs are in need of further study, being unreliable due to lack of control by the program office and high variability in implementation methods (ibid). Focusing on the more consistent householdbased TravelSmart programs will more effectively shift people away from driving, particularly as the decision to drive is frequently impacted by the behaviours and situation of the whole household (Brog et al., 2009). The school and workplace focus may be a strategy to find funding, since the Health Department is paying for the school programs and workplaces often pick up some costs (ACT Health, undated), but the savings are not worthwhile if the programs are ineffective. It is important to take a holistic view when allocating TravelSmart funding, as a successful household-based program can save the government money in road maintenance, health, and road accident compensation (Office of the Commissioner for Sustainability and the Environment, 2008).

\section{Flying in the face of the evidence}

The plan to expand Canberra's road network has no place in an evidence-based, holistic attempt to make transport more sustainable. From its low starting point, Canberra is facing increasing congestion over the next few decades (ACT Government, 2011). This can be viewed as either a problem or an opportunity. 
Congestion causes pollution and increased emissions from vehicles, but also slows private car travel time, making other modes more competitive (Van Exel and Rietveld, 2009). Managing congestion with traffic-light timing and travel advice programs can have positive effects, but in the end road capacity is the ultimate driver. The first priority for the ACT road network is stated as "completing key road infrastructure, improving capacity and maintaining our road assets" (ACT Government, 2011: 41). 'Completing' and 'improving' Canberra's already extensive road network will never ultimately solve our potential congestion problem. Governments the world over have discovered that you can't build your way out of the traffic; more roads simply attract more drivers at exactly the wrong time through 'induced demand' (Manning, 1984; Hutchinson, 2011). It's also an expensive option, and not what the public wants. Transport for Canberra opens with the finding that residents want around $20 \%$ of funds spent on maintaining our road network, with the rest used to improve our public and active transport facilities. Only five pages later, the government reports having spent around $\$ 380$ million on active and public transport, and over $\$ 700$ million on the road network this past decade, an extreme inverse of the public's stated preference (ACT Government, 2011: 7-12; Bresnan, 2011). People may not welcome drastic cuts in road spending to the extent indicated in the survey, but this is an opportunity to reconsider the ACT's funding priorities. Continuing to upgrade Canberra's already high quality road network will be an expensive way of perpetuating a reinforcing feedback cycle between the supply and demand of road space for private cars, undermining the government's efforts to make alternative modes more attractive and competitive (Mees et al., 2008; Pedal Power ACT, 2011).

\section{Near enough is not good enough: Missed opportunities}

While the ACT Government has good transport policy in some areas, Transport for Canberra is not holistic transport policy, and an opportunity to shift social norms has been missed. Not only do travel policies work far better when enacted as a complementary, holistic set (Marshall \& Banister, 2000; Ashton-Graham, 2008; Eriksson et al., 2010; Graham-Rowe et al., 2011), but rolling out the full set of policies at once creates the opportunity to have a public conversation about the many benefits of sustainable transport and raise environmental awareness. This has the potential to change the accepted social norms on car use, reaching out to those who have neutral attitudes - 'malcontented motorists' and 'complacent car addicts', and marginalising 'die-hard drivers' - those who refuse to consider other travel modes (Anable, 2005). This change of attitudes is another key element in the long-run effort to promote sustainable travel (Tribbia, 2007). The need to approach car-reduction policies from multiple angles is now 
well understood, with studies on active travel addressing parking pricing and TravelSmart programs (Krizek et al., 2009; Sinclair Knight Merz, 2009), TravelSmart literature commenting on PT improvements (Marshall \& Banister, 2000; Brog et al., 2009), and studies of reducing car use returning repeatedly to the principle of holistic transport policy (Graham-Rowe et al., 2011). Canberra has ignored this bigger picture in forming transport policy.

\section{Areas for future study}

Looking beyond good policy choices, a related area for study could be the issues that hinder their implementation. The ACT Government has struggled to deliver good transport policy, and continues to struggle, indicating that barriers must exist. It's not clear exactly where the buck stops on transport policy in Canberra - is it politicians, Treasury, ACTION? The relationship between political and bureaucratic barriers is complex and depends on perspective (Pers. comm., 2012a), with no clear way of moving forward. The multiple organisations and jurisdictions involved further complicate things, particularly the continued role of the National Capital Authority in the parliamentary triangle (Joint Standing Committee on the National Capital and External Territories, 2008). Add to this the possibility that reducing car use, while good for society, will make for unpopular policy facing opposition from car users and the way forward looks challenging indeed. Teasing out the political and bureaucratic issues to discover the best levers for change could be a fruitful area for future research.

\section{Conclusion}

Reducing car use is possible, but requires a holistic approach that is lacking in Canberra. Making the car experience less palatable and less popular in Canberra requires an understanding of the forces that influence people's transport decisions, and a willingness to address each of those forces through a holistic policy approach. Both push and pull measures are needed, with parking and road supply standing out as effective push measures, and good PT and active travel facilities as essential pull measures, all facilitated by the final step of getting drivers to rethink their habits through a behaviour change program. Success has benefits from the local to the global scale, including improved population health and social welfare. Canberra will miss out on potential benefits because the ACT Government is not effectively using key parts of good transport policy, most problematically road supply and evidence-based PT and behaviour change programs. Their approach remains piecemeal, with an admirable goal for reducing driving in Canberra but an inconsistent policy mix. Given the interdependent 
nature of the policy areas around car use and sustainable transport, it can be expected that this patchy attempt at making cars less attractive in Canberra will fall far short of the city's potential to shed its car dependence.

\section{Acknowledgements}

Heartfelt thanks to Rob Dyball for supervision and conceptual assistance, to two anonymous reviewers for their input, and to Eleanor, John and Janet for proofreading, conversations and support.

\section{References}

ACT Health, undated. Healthy Children and Young People. ACT Government. Available at http://health.act.gov.au/health-services/population-health/ health-promotion-branch/healthy-children-and-young-people (Accessed 22/03/12).

ACT Government, 2011. Transport for Canberra: Transport for a sustainable city 2012-2031.Available at http://www.transport.act.gov.au/policy.html (Accessed 11/10/12).

ACT Planning and Land Authority, 2007. Accommodating population change in the ACT. Available at http://apps.actpla.act.gov.au/spatialplan/1_future/1B_ context/1B6_population.htm (Accessed 31/0112).

ACTION, 2010a. 8:Dickson-O'Connor-City. ACT Government. Available at https:// www.action.act.gov.au/Routes_101001/pdfs/8_combined.pdf (Accessed 26/02/12).

ACTION, 2010b. 25, 225, 28: Weston-Woden-Campbell Park-Fairbairn Park. ACT Government. Available at https://www.action.act.gov.au/Routes_101001/ pdfs/28_combined.pdf (Accessed 26/02/12).

Anable, J., 2005. 'Complacent Car Addicts' or 'Aspiring Environmentalists'? Transport Policy 12: 65-78

Appleyard, D., 1976. Liveable urban streets: managing auto traffic in neighborhoods. Federal Highway Administration, Dept. of Transportation, Washington D.C.

ARRB Transport Research, 2002. Preliminary Evaluation of the Financial Impacts and Outcomes of the TravelSmart Individualised Marketing Program-Update. For WA Department for Planning and Infrastructure. Available at www. transport.wa.gov.au (Accessed 04/02/12) 
Ashton-Graham, C., 2008. Behavioural responses to peak oil and carbon pricing: Save 70 cents a litre by driving less. Department for Planning and Infrastructure, Perth, WA, Australia. Paper presented at Research Forum 2, October 2008. Planning and Transport Research Centre.

Australian Bureau of Statistics, 2009. Environmental Issues: Waste Management And Transport Use. Australian Bureau of Statistics. Available at http://www. abs.gov.au/AUSSTATS/abs@.nsf/Lookup/4602.0.55.002Main+Features1 M ar\%202009 (Accessed 13/01/12).

Australian Bureau of Statistics, 2011. 3218.0 Regional Population Growth, Australia. Available at http://www.abs.gov.au/ (Accessed 10/02/12).

Australian Greenhouse Office, 2006. Evaluation of Australian TravelSmart Projects in the ACT, South Australia, Queensland, Victoria and Western Australia: 2001-2005. Department of the Environment and Heritage, Australian Greenhouse Office. Available at www.travelsmart.gov.au (Accessed 25/01/12).

Bassett, D.R., Pucher, J., Buehler, R., Thompson, D.L. and Crouter, S.E., 2011. Active Transportation and Obesity in Europe, North America, and Australia. Institute of Transportation Engineers, 8: 24-28.

Beirao, G. and Carbal, J.A.S., 2007. 'Understanding attitudes towards public transport and private car: A qualitative study'.Transport Policy 14: 478-489

Besser, L.M. and Dannenberg, A.L., 2005. 'Walking to Public Transit: Steps to Help Meet Physical Activity Recommendations'.American Journal of Preventive Medicine, 29(4): 273-280.

Bresnan, A., 2011. Submission to Draft Transport for Canberra Plan. ACT Greens. Available at www.act.greens.org.au (Accessed 05/02/12).

Brog, W., Erl, E., Ker, I., Ryle, J. and Wall, R., 2009. 'Evaluation of voluntary travel behaviour change: Experiences from three continents'.Transport Policy 16: 281-292

Canberra Pedestrian Forum, 2011. Submission on Transport for Canberra. Canberra Pedestrian Forum. Available at http:/grapevine.net. etau/ mccluskeyarundell/pedestrian.html (Accessed 06/02/12).

Canberra Times, 2011. 'Car-dependent “disaster".Canberra Times, 7 November, 2011 http://www.canberratimes.com.au/act-news/cardependent-disaster20111106-1v20h.html (Accessed 30/1/2012). 
The ANU Undergraduate Research Journal

Cardno Eppell Olsen, 2011. ACT Cycling and Pedestrian Network - Priority Network for Capital Works. Territory and Municipal Services, Roads ACT. Available at www.tams.act.gov.au (Accessed 15/02/12).

Collins, C.M, and Chambers, S.M., 2005. 'Psychological and Situational Influences on Commuter-Transport-Mode Choice'. Environment and Behavior, 37(5): 640-661.

Cools, M., Moons, E., Janssens, B. and Wets, G., 2009. 'Shifting towards environment-friendly modes: travellers using Q-methodology'. Transportation $36: 437-453$

Eriksson, L., Nordlund, A.M. and Garvill, J., 2010. 'Expected car use reduction in response to structural travel demand management measures'.Transportation Research Part F 13: 329-342.

Graham-Rowe, E., Skippon, S., Gardner, B. and Abraham, C., 2011. Can we reduce car use and, if so, how? A review of available evidence. Transportation Research Part A 45: 401-418

Hass-Klau, C., Crampton, G., Weidauer, M. and Deutsch, V., 2000. Bus or Light Rail: Making the Right Choice. Environmental and transport planning, Brighton.

Hutchinson, N., 2011. 'Improving Pedestrian Access Across Arterial Roads'. Department of Transport, Victoria, Australia. Presented at the State of Australian Cities National Conference, 29 November to 2 December 2011.

Joint Standing Committee on the National Capital and External Territories, 2008. The Way Forward: Inquiry into the role of the National Capital Authority, Parliament of Australia. Available at http://www.aph.gov.au/house/ committee/ncet/natcapauth/report.htm (Accessed 14/01/12).

Krizek, K.J., Forsyth, A. and Baum, L., 2009. Walking and Cycling International Literature Review. Department of Transport, Victoria. Available at www. transport.vic.gov.au (Accessed 06/02/12)

Loukopoulos, P., Jakobsson, C., Garling, T., Schneider, C.M. and Fujii, S., 2005. 'Public attitudes towards policy measures for reducing private car use: evidence from a study in Sweden'. Environmental Science \& Policy 8: 57-66.

Manning, I., 1984. Beyond Walking Distance: the gains from speed in Australian urban travel. Australian National University Press, Canberra.

Marshall, S. and Banister, D., 2000. 'Travel reduction strategies: intentions and outcomes'. Transportation Research Part A 34: 321-338. 
Mees, P., 2009. 'How dense are we? Another look at urban density and transport patterns in Australia, Canada and the USA'. Paper presented at State of Australian Cities Conference, Perth, 25 November 2009. School of Global Studies, Social Science \& Planning, RMIT.

Mees, P., 2011. Submission in response to Transport for Canberra. Available at http://images.canberratimes.com.au/file/2012/07/30/3510331/Mees $\% 2520$ submission \% 2520\% 2520Transport \% 2520for \% 2520 Canberra. pdf?rand=1343613343071(Accessed 30/1/2012).

Mees, P., O'Connell G. and Stone J., 2008. 'Travel to Work in Australian Capital Cities, 1976-2006'. Urban Policy and Research, 26(3): 363-378.

Moriarty, P. and Honnery, D., 2008. 'The prospects for global green car mobility'. Journal of Cleaner Production, 16: 1717-1726.

Office of the Commissioner for Sustainability and the Environment, 2008. ACT State of the Environment 2007/08. Available at http://www.envcomm.act. gov.au/publications/soe/2007actreport (Accessed 15/01/12).

Pedal Power ACT, 2011. Submission on Draft Transport for Canberra Plan. Pedal Power. Available at www.pedalpower.org.au (Accessed 05/02/12).

Planning Institute Australia, 2011. PIA Response. Planning Institute Australia, A.C.T Division. Available at www.planning.org.au (Accesssed 06/02/12).

Prillwitz, J. and Barr, S., 2011. 'Moving towards sustainability? Mobility styles, attitudes and individual travel behaviour'. Journal of Transport Geography 19: $1590-1600$

Santos, G., Behrendt, H. and Teytelboym, A., 2010. 'Part II: Policy instruments for sustainable road transport'. Research in Transportation Economics 28: 4691.

Sinclair Knight Merz, 2009. Cycling and Walking Strategy Feasibility Study. ACT Government. Available at www.transport.act.gov.au (Accessed 30/01/12).

Stradline, S.G., Meadows, M.L. and Beatty, S., 2000. 'Helping drivers out of their cars: Integrating transport policy and social psychology for sustainable change'.Transport Policy 7: 207-215

Taylor, M.A.P. and Ampt, E.S., 2003. 'Travelling smarter down under: policies for voluntary travel behaviour change in Australia'.Transport Policy 10: 165177 
The ANU Undergraduate Research Journal

Territory and Municipal Services, 2011. Territory and Municipal Services Directorate Annual Report 2010-2011, volume 2. ACT Government. Available at www.tams.act.gov.au (Accessed 20/02/12).

Tranter, P. and May, M., 2005. Using the Concept of Effective Speed as a Stimulus for Travel Behaviour Change and Policy Development. Department of the Environment and Heritage, Australian Greenhouse Office.

Tribbia, J., 2007. Stuck in the slow lane of behaviour change? A not-so-superhuman perspective on getting out of our cars, in Creating a Climate for Change: Communicating Climate Change and Facilitating Social Change, eds Moser, S. and Dilling, L., Cambridge: Cambridge University Press, pp. 237-250

Van Exel, N.J.A., Rietveld, P., 2009. 'Could you also have made this trip by another mode? An investigation of perceived travel possibilities of car and train travellers on the main travel corridors to the city of Amsterdam, The Netherlands'.Transportation Research Part A 43: 374-385.

Victorian Transport Policy Institute, 2011. Transportation Cost and Benefit Analysis II - Vehicle Costs. Victoria Transport Policy Institute. Available at www.vtpi.org (Accessed 20/03/12).

Walker, J., 2008. "Be on the Way!" Creating Attractive Public Transport for a Sustainable Canberra . McCormick Rankin Cagney. Paper presented at ACTPLA Sustainable Transport Workshop, 18 September, 2008.

Wardman, M., Tight, M. and Page, M., 2007. 'Factors influencing the propensity to cycle to work.'Transportation Research Part A: Policy and Practice, 41(4): 339-350

Wedderburn, 2011. Making Walking Count-Canberra. Walk21. Available at www.transport.act.gov.au (Accessed 10-02-12).

Women's Centre for Health Matters, 2011. Submission on Transport for Canberra: Transport for a sustainable city 2011-2031. Available at www.wchm.org.au (Accessed 09/02/12).

\section{Personal communications}

Pers. comm., 2012a. Interview with Amanda Bresnan, ACT Greens. 30 January 2012, Canberra.

Pers. comm., 2012b. Interview with Adam Taylor, ANU Green. 6 February 2012, Canberra. 